\title{
Efficacy of a Monthly Compared to 3-Monthly Depot GnRH Analogue (Goserelin) in the Treatment of Children with Central Precocious Puberty
}

\author{
H. Isaac ${ }^{a} \quad$ L. Patel ${ }^{a}$ b S. Meyer ${ }^{b}$ C.M. Hall ${ }^{a}$ C. Cusick ${ }^{c}$ D.A. Price ${ }^{a} \quad$ P.E. Clayton ${ }^{a, b}$ \\ ${ }^{a}$ Department of Paediatric Endocrinology, Royal Manchester Children's Hospital, ${ }^{b}$ Academic Unit of Child Health, \\ The University of Manchester, and 'Biochemistry Laboratory, Royal Manchester Children's Hospital, Manchester, UK
}

\section{Key Words}

Early puberty $\cdot$ Pubertal suppression • Body mass index • Obesity

\begin{abstract}
Aims: To compare the efficacy of goserelin $10.8 \mathrm{mg}$ (Zoladex LA - ZLA) administered 9-12 weekly with 3.6 mg (Zoladex Z) given monthly in suppressing pubertal development, and effect on body mass index (BMI). Methods: Children with central precocious puberty (CPP) treated with $Z(n=34)$ or ZLA $(n=28)$ were studied retrospectively. Pubertal scores and BMI SDS during 24 months' treatment were compared. Results: To attain adequate pubertal suppression, more patients on ZLA than Z required increase in injection frequency $(p=0.02)$ and this was so for $7 / 8$ patients with a structural aetiology for CPP on ZLA and 2/8 on Z. A greater proportion of patients on ZLA had BMI $>+2$ SDS before $(p=0.05)$, and at 18 and 24 months ( $p=0.02$ and 0.04 ). BMI SDS transiently increased during the first 6 months on ZLA ( $p=0.04)$. Conclusion: Both Z and ZLA were effective in suppressing puberty. To achieve adequate suppression, increased injection frequency was more likely with ZLA than Z, and particularly in patients with structural defects. Children with CPP had an elevated BMI at the onset of therapy and ZLA had a transient positive influence on BMI.

Copyright $\odot 2007$ S. Karger AG, Basel
\end{abstract}

\section{Introduction}

GnRH analogues have become the treatment of choice for central precocious puberty (CCP) at our centre since 1992. They act via desensitization and downregulation of pituitary GnRH receptors, so that gonadotrophin release is gradually inhibited after an initial stimulatory agonist phase [1]. In addition to depot GnRH analogues delivered as monthly injections, longer-acting preparations with a duration of action over 3 months have recently been introduced. While such longer-acting preparations potentially provide greater convenience for the child and family, as yet there are limited data on their efficacy compared to the one-month formulation [2-6]. Suppression of gonadotrophin levels in children with CPP has been found to be comparable for the one- and three-month preparations of leuprorelin [2, 3] and triptorelin [4] given for 3-12 months. Other investigators have reported the results of longer duration of treatment with goserelin $[5,6]$. In 12 girls with $\mathrm{CPP} /$ early puberty (EP) treated with the long-acting depot goserelin $10.8 \mathrm{mg}$ (Zoladex ${ }^{\circledR}$ LA (ZLA); AstraZeneca, Cheshire, UK) (mean duration of treatment 2.9 years), $\mathrm{Pa}$ terson et al. [5] reported that ZLA was effective in controlling CPP when given every 9-12 weeks. In a larger study of 49 patients (mean duration of treatment 18 months), Trueman et al. [6] found that while ZLA induced a significant reduction in gonadotrophins at 12 weeks, the suppression was waning by 12 weeks in $13 \%$ of patients not previously

Dr. Leena Patel

University of Manchester, Academic Unit of Child Health

Booth Hall Children's Hospital

Manchester M9 7AA (UK)

Tel. +44 161918 5536, Fax +44 161740 6239, E-Mail lp@manchester.ac.uk 
Table 1. Clinical score to evaluate progress of pubertal development (maximum score 10)

\begin{tabular}{ll}
\hline Clinical features & Score \\
\hline Breast/testicular enlargement & $\begin{array}{l}2 \text { for increase in size, } 1 \text { for no } \\
\text { change or decrease in size }\end{array}$ \\
\hline Pubic/axillary hair & $\begin{array}{l}2 \text { for increase, 1 for no change } \\
\text { or decrease }\end{array}$ \\
\hline Facial hair in males & 2 \\
\hline Vaginal bleeding/discharge & 2 \\
\hline Linear growth acceleration & $\begin{array}{l}\text { or for increase, } 0 \text { for no change } \\
\text { or decrease }\end{array}$ \\
\hline Acne & 1 \\
\hline $\begin{array}{l}\text { Mood swings (e.g. erratic volatile state of mind } \\
\text { including angry, irritable, overly sensitive and sad) }\end{array}$ & 1 \\
\hline Behavioural changes (e.g. aggressive or rebellious) & 0.5 \\
\hline Body odour & 0.5 \\
\hline
\end{tabular}

treated and $27 \%$ who had previously received short-acting $\mathrm{GnRH}$ analogues. This highlighted the need to investigate further the correlation between gonadotrophin suppression and clinical evidence of pubertal suppression.

Weight gain during $\mathrm{GnRH}$ analogue treatment has been of particular concern for some patients. A number of investigators noted patients were relatively overweight at diagnosis and BMI pre-treatment was the best predictor of BMI at the end of treatment [7-10]. Lazar et al. [11] observed more pronounced weight gain in girls with early rapidly progressive puberty during treatment with 4weekly GnRH analogue compared to untreated girls. However, the excessive weight gain was arrested after stopping treatment and by the time final height was achieved, body mass index (BMI) was similar in the treated and untreated groups.

In this retrospective observational study, we have aimed (1) to compare the efficacy of depot goserelin 10.8 $\mathrm{mg}$ (ZLA) with the shorter-acting goserelin $3.6 \mathrm{mg}$ (Z) in suppressing pubertal development and growth acceleration, and (2) to assess the effect of each preparation on change in BMI.

\section{Methods}

Patients

We carried out a retrospective analysis of 128 patients with central precocious puberty (CPP)/early puberty treated with $\mathrm{Z}$ or ZLA over a 12 -year period. CPP was defined as the onset of pu- bertal signs or symptoms before age 8 years in girls and 9 years in boys. Early puberty was defined as the onset of puberty between age $8-10$ years in girls and $9-11$ years in boys.

Subjects were included only if they had been treated with $\mathrm{Z}$ or ZLA for a minimum of 1 year. Those previously treated with another GnRH analogue for more than 3 months or who had a condition known to affect growth (such as leukaemia, congenital adrenal hyperplasia, skeletal dysplasia, growth hormone deficiency, intrauterine growth retardation, Turner syndrome with spontaneous early puberty, moderate or severe cerebral palsy) were excluded. The majority of patients had neuroimaging to determine the aetiology of precocious puberty.

\section{Methods}

The diagnosis of puberty was based on combinations of the following criteria:

1 A history of pubertal symptoms.

2 Signs of pubertal development defined by Tanner standards.

3 Increased growth velocity with or without height SDS $>2$.

4 Advanced bone age as determined by Greulich and Pyle standards.

5 In females, appearances of uterus and ovaries on pelvic ultrasound consistent with pubertal development.

6 Pubertal response to a GnRH stimulation test (peak $\mathrm{LH}>5.0$ $\mathrm{U} / 1[12]) \pm$ elevated oestradiol/testosterone levels.

A clinical score was designed to evaluate the degree of pubertal progression at the onset of treatment and 6 monthly thereafter (table 1). Clinical suppression was considered adequate if the clinical score reduced. It was considered inadequate if the clinical score increased or failed to decrease during the first year of therapy when pubertal signs and/or symptoms are expected to regress with treatment. Clinical examination for the pubertal progress score was undertaken by experienced paediatric endocrinologists (DAP, PEC, LP and CMH). 
Table 2. Clinical characteristics of the subjects treated with Zoladex and Zoladex LA

\begin{tabular}{|c|c|c|c|c|}
\hline & \multicolumn{2}{|l|}{ Zoladex } & \multicolumn{2}{|l|}{ Zoladex LA } \\
\hline & males $(\mathrm{n}=1)$ & females $(n=33)$ & males $(n=5)$ & females $(n=23)$ \\
\hline \multicolumn{5}{|l|}{ Patients by diagnosis, n (\%) } \\
\hline Idiopathic & & $22 / 33(68 \%)$ & $1 / 5(20 \%)$ & $17 / 23(74 \%)$ \\
\hline Syndromic* & & $4 / 33(12 \%)$ & $2 / 5(40 \%)$ & 0 \\
\hline Structural brain pathology & 1 & $7 / 33(20 \%)$ & $2 / 5(40 \%)$ & $6 / 23(23 \%)$ \\
\hline Structural brain pathology & $\begin{array}{l}\text { hypothalamic } \\
\text { hamartoma (1) }\end{array}$ & $\begin{array}{l}\text { hypothalamic hamarto- } \\
\text { ma ( } 1) \text {, pineal cyst }(2) \text {, } \\
\text { hydrocephalus ( } 3) \text {, sub- } \\
\text { dural haemorrhage (1) }\end{array}$ & $\begin{array}{l}\text { suprasellar astrocyto- } \\
\text { ma (1), focal abnor- } \\
\text { mality in left hemi- } \\
\text { sphere (1) }\end{array}$ & $\begin{array}{l}\text { hypothalamic hamartoma } \\
\text { (2), suprasellar astrocytoma } \\
\text { (1), neurofibromatosis and } \\
\text { brainstem glioma (1), left } \\
\text { porencephalic cyst (1), hy- } \\
\text { drocephalus (1) }\end{array}$ \\
\hline
\end{tabular}

* Presence or suspicion of a syndrome and/or non-specific brain injury.

\section{Auxological Assessment}

For each subject, height and BMI at the start of GnRH analogue treatment and at $6,12,18$ and 24 months into treatment were expressed as standard deviation scores (SDS) using the 1990 UK reference data $[13,14]$. Comparison of growth performance over 2 years was made on changes in height and BMI SDS over each 6-month period and over cumulative periods up to 2 years both within and between the $\mathrm{Z}$ and ZLA groups. In addition growth performance was compared to that expected in normal children, who on average would be expected to have no change in SDS. Bone age at the start of treatment and annually thereafter was expressed as a ratio to chronological age.

\section{Treatment and Biochemical Evaluation}

In addition to oestradiol and testosterone levels, a GnRH stimulation test was performed at diagnosis. Blood samples for LH and FSH were taken at baseline and at 30 and 60 min after an intravenous bolus of GnRH $100 \mu \mathrm{g}$. Between 1992 to 1998, patients commenced treatment with goserelin $3.6 \mathrm{mg}$ (Z group) and thereafter treatment was started with goserelin $10.8 \mathrm{mg}$ (ZLA group) by subcutaneous injection. In the latter, oestradiol/ testosterone levels and GnRH test were repeated 8 and 12 weeks later [6]. Treatment frequency was increased if the clinical score (table 1) failed to decrease, and/or peak LH with the GnRH test was $>2$ U/1 [6]. Paediatric endocrine nurses organised treatment so that it was least disruptive to families and were responsible for administering the treatment. Thus compliance was excellent.

\section{Assays}

Serum FSH and LH were measured by DELFIA fluoroimmunoassays (Wallac Oy, Turku, Finland). The intra- and interassay coefficients of variation were 2.2 and $3.5 \%$ for $\mathrm{LH}$, and 2.3 and $1.9 \%$ for $\mathrm{FSH}$, respectively. The minimal detectable concentration (MDC) was 0.2 IU/l for both LH and FSH. Serum oestradiol concentrations were determined by DELFIA fluoroimmunoassays (Wallac Oy, Turku, Finland) and testosterone by Architect che- miluminescent assay (Abbott Laboratories, Berkshire, UK). Assay performance is such that accurate extrapolation below the MDC can be made but for clinical use a conservative MDC is reported. Thus, for statistical analysis, levels below the MDC for gonadotrophins, oestradiol and testosterone were assigned 0.1 $\mathrm{IU} / \mathrm{l}, 40 \mathrm{pmol} / \mathrm{l}$ and $0.4 \mathrm{nmol} / \mathrm{l}$, respectively.

\section{Statistical Analysis}

Growth performance was compared within the groups by ANOVA, and across the groups by t tests. Gonadotrophin values were not normally distributed and non parametric tests (MannWhitney and Wilcoxon signed-rank) were used to examine group differences. The $\chi^{2}$ test was used for differences in frequencies in group data. Relationships between variables were assessed with Spearman's rank correlation.

\section{Results}

\section{Clinical Characteristics}

The study included 58 patients with CPP and 4 with early puberty (table 2). 16 subjects had defined organic CNS pathology (table 2). Their height and BMI SDS pretreatment was not significantly different from the other patients in the $\mathrm{Z}$ and ZLA groups. At the start of treatment, the $\mathrm{Z}$ and ZLA groups were comparable for age (median 7.2 vs. 7.5 years) and bone age/calendar age (median 1.2 vs. 1.2). Three boys and 2 girls in the ZLA group and 4 girls in the $Z$ group had learning difficulties/developmental delay. 
Table 3. Incremental change in height SDS during treatment and cumulative effect on height suppression by length of time on treatment with Zoladex and Zoladex LA

\begin{tabular}{llllll}
\hline Time on treatment & \multicolumn{2}{l}{$\begin{array}{l}\text { Mean incremental change in } \\
\text { height SDS }(\mathrm{n})\end{array}$} & $\begin{array}{l}\text { Length of time on } \\
\text { treatment, months }\end{array}$ & \multicolumn{2}{l}{$\begin{array}{l}\text { Mean cumulative change in } \\
\text { height SDS (n) }\end{array}$} \\
\cline { 2 - 3 } & Zoladex & Zoladex LA & & Zoladex & Zoladex LA \\
\hline 0-6 months & $0.03(34)$ & $-0.05(27)$ & $0-6$ & $0.03(34)$ & $-0.05(27)$ \\
6-12 months & $-0.07(34)$ & $-0.02(27)$ & $0-12$ & $-0.04(34)$ & $-0.06(28)$ \\
$12-18$ months & $-0.12(28)$ & $-0.05(23)$ & $0-18$ & $-0.18(28)$ & $-0.14(23)$ \\
$18-24$ months & $-0.14(20)$ & $-0.09(14)$ & $0-24$ & $-0.35(20)^{*}$ & $-0.33(14)$ \\
\hline
\end{tabular}

${ }^{*} \mathrm{p}=0.001$ within group.

Table 4. Incremental change in BMI SDS during treatment and cumulative effect on change in BMI by length of time on treatment with Zoladex and Zoladex LA

\begin{tabular}{|c|c|c|c|c|c|}
\hline \multirow[t]{2}{*}{ Time on treatment } & \multicolumn{2}{|c|}{$\begin{array}{l}\text { Mean incremental change in } \\
\text { BMS SDS (n) }\end{array}$} & \multirow[t]{2}{*}{$\begin{array}{l}\text { Length of time on } \\
\text { treatment, months }\end{array}$} & \multicolumn{2}{|c|}{$\begin{array}{l}\text { Mean cumulative change in } \\
\text { BMS SDS (n) }\end{array}$} \\
\hline & Zoladex & Zoladex LA & & Zoladex & Zoladex LA \\
\hline $0-6$ months & $0.02(34)$ & $0.19(27)^{*}$ & $0-6$ & $0.02(34)$ & $0.19(27)$ \\
\hline 6-12 months & $0.08(34)$ & $0.01(27)$ & $0-12$ & $0.09(34)$ & $0.20(28)$ \\
\hline $12-18$ months & $0(27)$ & $-0.03(23)$ & $0-18$ & $0.08(27)$ & $0.16(23)$ \\
\hline 18-24 months & $0.10(19)$ & $-0.01(14)$ & $0-24$ & $0.19(19)$ & $0.04(14)$ \\
\hline
\end{tabular}

${ }^{*} \mathrm{p}=0.04$ within group.

\section{Baseline Data}

\section{Auxology}

At the start of treatment mean height SDS was increased but comparable in both groups, indicating that the children had experienced a period of accelerated growth associated with their CPP (mean +1.5 SDS, range 1.0-2.0 for $\mathrm{Z}$ and +1.8 SDS, range 1.2-2.4 for ZLA; $\mathrm{p}=$ $0.4)$. Similarly, mean BMI SDS was increased at the onset of treatment in both groups (mean +1.3 SDS, range 0.91.6 for $\mathrm{Z}$ and mean $+1.6 \mathrm{SDS}$, range $1.2-2.0$ for $\mathrm{ZLA} ; \mathrm{p}=$ $0.1)$.

\section{GnRH Stimulation Tests}

At diagnosis, there was no significant difference in the number of cases with an $\mathrm{LH}$ dominant pattern in the $\mathrm{Z}$ and ZLA groups (45 vs. $32 \%$; $p=0.4$ ). However, peak LH was significantly higher in the $\mathrm{Z}$ group (median 12.9, range 2.0-40.0 vs. ZLA: median 4.3, range 0.7-69.9 IU/l; $\mathrm{p}=$ 0.002). 24 patients ( 7 in $Z$ and 17 in ZLA group) had peak $\mathrm{LH}$ levels $<5.0 \mathrm{IU} / \mathrm{l}$ at diagnosis. The clinical features in all
24 patients supported the diagnosis of central precocious puberty (median clinical score 6.5 for Z and 6 for ZLA, range 3-9.5); treatment was commenced on this basis.

\section{Evaluation on Treatment}

Auxology

Treatment with both Z and ZLA was associated with a decrease in height SDS over the 2 years but was only significant in the $Z$ group $(\mathrm{p}=0.001)$ (table 3$)$. Compared to children with a normal growth rate, the decrease in height SDS in the $\mathrm{Z}$ group was significant at 1.5 and 2 years ( $p=0.03$ and 0.003 , respectively), and the decrease in height SDS for the ZLA group was significant at 2 years $(p=0.03)$. The median ratio of bone age to chronological age (BA/CA) was 1.2 in both groups at the start of treatment, but in neither group did this ratio advance further during treatment.

BMI SDS during treatment did not differ significantly between the $Z$ and ZLA groups or between the diagnostic subgroups. Neither the patients with hypothalamic ham- 
artomas ( 2 in the $\mathrm{Z}$ group and 2 in the ZLA group) nor those with other structural CNS abnormalities had higher BMI SDS at baseline or during treatment compared to other patients. Although it did not change significantly over the 2 years in either group, BMI SDS increased during the first 6 months on treatment in the ZLA group $(\mathrm{p}=0.04)$ (table 4). A greater proportion of patients in the ZLA group compared to Z group had BMI $>+2$ SDS before treatment ( 43 vs. $20 \%, p=0.05$ ), and at 18 and 24 months on treatment ( 48 vs. $18 \%, p=0.02$ and 50 vs. $16 \%$, $\mathrm{p}=0.04$, respectively). Pre-treatment BMI SDS but not bone age or clinical score correlated significantly with BMI SDS at 24 months on treatment $\left(\mathrm{Zr}=0.70, \mathrm{r}^{2}=46 \%\right.$; ZLA $r=0.77, r^{2}=60 \% ; p=0.001$ ).

The trends in changes in height and BMI SDS were similar when those individuals who completed 24 months follow up were considered on their own ( $\mathrm{Zn}=20$ and ZLA n = 14).

\section{Clinical Suppression}

In the $\mathrm{Z}$ and ZLA groups, the clinical score at the start of treatment was comparable, remained suppressed from 6 to 24 months on treatment (fig. 1) and the proportion of patients with adequate suppression did not differ $(88$ vs. $81 \%$ at 12 months, $\mathrm{p}=0.7 ; 83$ vs. $58 \%$ at 24 months, $\mathrm{p}=0.2$ ). However, to attain adequate clinical and/or biochemical suppression a greater proportion of patients in the ZLA than $\mathrm{Z}$ group required an increase in injection frequency: $20 / 28$ (71\%) on ZLA received treatment at 6 to 10 -weekly intervals while $15 / 34(44 \%)$ on $\mathrm{Z}$ had 3weekly injections, $p=0.02$ ). In the $Z$ group, an increase in injection frequency was necessary in the 1st year for 13 and in the 2 nd year for 2 patients (1.2 and 1.6 years after starting treatment). Of these, only one patient had vaginal bleeding in the 1st year of treatment. In the ZLA group, an increase in injection frequency was necessary in the 1st year for 19 and in the 2nd year for one patient (1.5 years after starting treatment). Of these 20, the frequency of injections was 10-weekly in 7, 8 -weekly in 8 and 6 -weekly in 5 patients. None of these patients menstruated while being treated. The 5 patients in the ZLA group requiring 6-weekly injections did not differ from the others in aetiology (3 idiopathic and 2 structural abnormalities), age (median 5.9 vs. 6.1 years) or clinical score (median 6 vs. 6). Although not statistically significant, they had relatively higher baseline BMI SDS (mean 1.9 vs. 1.5, $\mathrm{p}=0.3$ ) and height SDS (mean 2.4 vs. $1.3, \mathrm{p}=0.2$ ). Delta peak $\mathrm{LH} / \mathrm{FSH}$ ratio at 12 weeks and the delta clinical score in the first 6 months of treatment in the ZLA group did not correlate significantly $(r=0.04)$.

Monthly versus 3-Monthly GnRH Analogue for Precocious Puberty

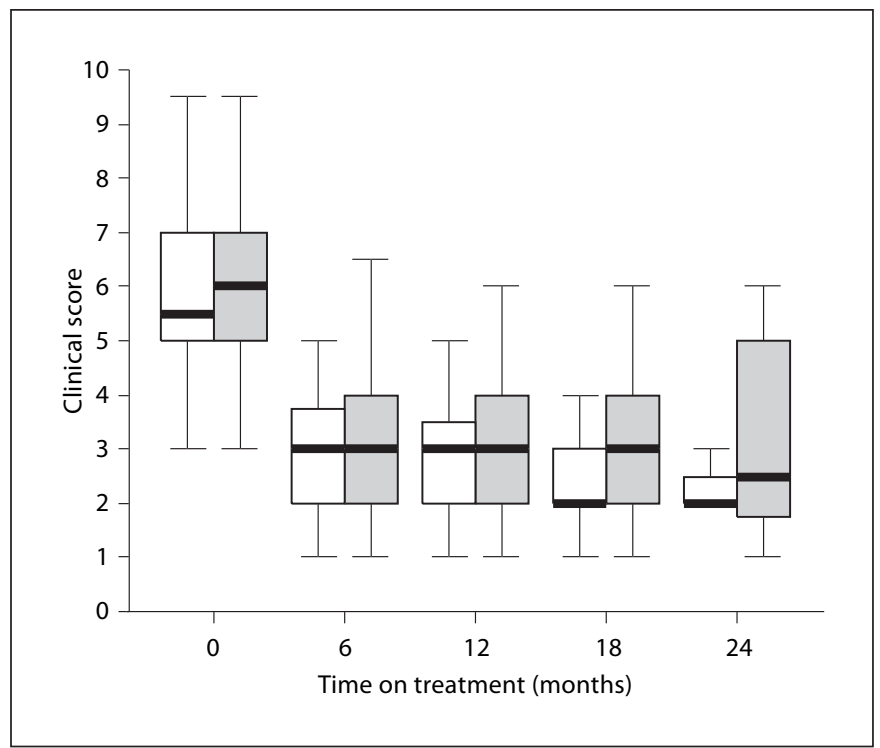

Fig. 1. Clinical scores for Zoladex (white boxes) and Zoladex LA (grey boxes) groups over 24 months on treatment. Box and whisker plots represent median, interquartile range and range.

In the subgroups that did or did not have an increase in injection frequency in each treatment group, there were no significant differences in clinical scores or age at the start of treatment. Seven of the 8 patients with a structural aetiology for CPP in the ZLA group required an increase in injection frequency compared to $2 / 8(25 \%)$ in the $\mathrm{Z}$ group but no such differences were observed in the other diagnostic subgroups. Although numbers were small, there were no clear differences in structural defects, LH dominance and problems with control in boys compared to girls in the two treatment groups.

\section{Discussion}

We evaluated the efficacy of GnRH analogue treatment over a 12 -year period. This coincided with the obesity trend in the UK and a change in treatment from $\mathrm{Z}$ to ZLA. Thus, patients seen in the latter half of this period and treated with ZLA were relatively heavier and a greater proportion had BMI $>+2$ SDS compared to patients treated in the earlier years and with Z. The ZLA patients were also noted to have lower peak LH levels at diagnosis than the $\mathrm{Z}$ group. This may be related to a negative effect of BMI on LH response as well as a negative effect of excess leptin on the central reproductive system of obese

Horm Res 2007:68:157-163 
girls as alluded to by Bouvattier et al. [15]. The wide range of peak LH levels in the ZLA group suggests that children with a greater range of pubertal activation presented during the ZLA era. However, the proportion of children with $\mathrm{LH}$ dominance did not differ in the two periods (45 vs. $32 \%)$.

Both goserelin preparations were effective in controlling pubertal growth acceleration but height suppression seemed more pronounced in the $\mathrm{Z}$ group. This difference in efficacy was significant when compared within the groups and to a normal population but not when compared against each other. The effect on linear growth suppression as time progressed appeared cumulative. Therefore, the longer the duration of treatment with the GnRH analogue, the more pronounced was the effect on height suppression. This corresponded with further advance in bone age being arrested and is in keeping with the observations of Weise et al. [16]. Explanations proposed for the growth suppression during $\mathrm{GnRH}$ analogue treatment include reduced GH secretion [17] and premature growth plate senescence [16]. Weise et al. [16] found height velocity during treatment correlated inversely with bone age. Using the latter as a surrogate marker of growth plate senescence, they suggested that impaired growth during treatment, akin to catch-down growth, is partly due to premature growth plate senescence induced by previous oestrogen exposure.

Children with CPP tend to have a high incidence of obesity but this does not appear to be related to GnRH analogue administration in the long term [7-11, 18-20]. This is not surprising considering the recognised association between obesity and earlier onset of puberty [21].

During treatment, a transient increase in BMI was seen in the ZLA group but there was no change in mean BMI by 2 years on treatment. Hence, any weight gain associated with the longer-acting $\mathrm{GnRH}$ analogue is temporary and should not be a reason for avoiding it. This is further supported by observations of shorter treatment periods being associated with greater BMI [10] and lower BMI after stopping treatment than at the start or during treatment [9-11, 18-20]. Feuillan et al. [8] found obesity, at initial presentation, during treatment and subsequently, was more frequent in children with hypothalamic hamartomas than those with idiopathic CPP. In our study, there were only 4 patients with hypothalamic hamartomas and they were not more obese compared to other patients. Although it is arguable whether BMI truly represents adiposity in children with precocious puberty at different ages and stages of maturation [22], our obser- vations are consistent with longitudinal changes in body composition assessed by DEXA in children with precocious puberty $[20,23]$. Together these studies found percent fat was increased at baseline, increased initially during GnRH analogue treatment, but decreased and normalised within 1 year of stopping treatment [20,23].

While the proportion of patients with adequate clinical suppression was similar in both treatment groups, this was at the expense of more frequent injections in the ZLA group. With triptorelin $11.25 \mathrm{mg} 3$-month depot, Carel et al. [4] found GnRH-stimulated peak LH was suppressed ( $\leq 3 \mathrm{IU} / \mathrm{l})$ in $85 \%$ of the children at 3 months, $97 \%$ at 6 months and $95 \%$ at 12 months of treatment, and pubertal development regressed in most patients. In children given different doses of leuprolide sequentially ( 7.5 $\mathrm{mg}$ every 4 weeks for a minimum of 24 weeks, $3.75 \mathrm{mg}$ every 4 weeks for 12 weeks and $11.25 \mathrm{mg}$ with assessment after 3 months), Badaru et al. [2] noted higher LH and FSH levels with both $3.75 \mathrm{mg}$ and $11.25 \mathrm{mg}$ at 3 months compared with $7.5 \mathrm{mg}$. These investigators did not describe the effect of treatment on pubertal development. We observed adequate biochemical suppression at 12 weeks in $95 \%$ of children treated with ZLA but this did not correlate with the change in clinical scores or the change in peak LH/FSH ratio. Although useful as a diagnostic tool, the GnRH stimulation test was not helpful in monitoring pubertal suppression. Serial LHRH monitoring also has important resource implications as well as requiring venepuncture, time off school, and time off work, for the child and parent, respectively, and should not therefore be performed routinely. Brito et al. [24] found peak LH levels $2 \mathrm{~h}$ after depot leuprolide to be more reliable and convenient than the GnRH test for monitoring treatment but similar evaluations of LH levels after goserelin administration have not been undertaken. Thus, the decision to increase the dose of GnRH analogue as suggested by Badaru et al. [2] or frequency of injections should be made on symptomatology and clinical evidence of progression of puberty.

We tried to identify a group of patients in whom the efficacy of GnRH analogue waned towards the end of the treatment cycle and thus necessitated an increase in injection frequency. A younger age group, higher clinical scores and higher LH/FSH did not influence the efficacy of GnRH analogue treatment. However, precocious puberty associated with a structural defect was more likely to respond to $\mathrm{Z}$ treatment without the need for an increase in injection frequency in contrast to ZLA when $7 / 8$ children required an increase in injection frequency. 
In conclusion, we have shown that both the short- $(\mathrm{Z})$ and long-acting (ZLA) depot goserelin are effective in suppressing the progression of pubertal signs and symptoms. Children with CPP had an elevated BMI for chronological age at the onset of therapy and there is a positive but transient influence on BMI during treatment with ZLA. Z seems to be more effective in suppressing growth acceleration. To achieve adequate pubertal suppression more children on ZLA required an increase in injection frequency than those on $\mathrm{Z}$. This was most notable for patients with structural defects. Nevertheless, in general our preference is to initiate treatment with ZLA as the overall number of injections is fewer than would be required for $\mathrm{Z}$.

\section{References}

1 Conn PM, Crowley WF: Gonadotropin-releasing hormone and its analogues. N Engl J Med 1991;324:93-103.

-2 Badaru A, Wilson DM, Bachrach LK, Fechner P, Gandrud LM, Durham E, Wintergerst K, Chi C, Klein KO, Neely KE: Sequential comparisons of one-month and three-month depot leuprolide regimens in central precocious puberty. J Clin Endocrinol Metab 2006;91:1862-1867.

- 3 Carel JC, Lahlou N, Jaramillo O, Montauban V, Teinturier C, Colle M, Lucas C, Chaussain JL: Treatment of central precocious puberty by subcutaneous injections of leuprorelin 3month depot $(11.25 \mathrm{mg})$. J Clin Endocrinol Metab 2002;87:4111-4116.

-4 Carel JC, Blumberg J, Seymour C, Adamsbaum C, Lahlou N, Triptorelin 3-Month CPP Study Group: Three-month sustained-release triptorelin $(11.25 \mathrm{mg})$ in the treatment of central precocious puberty. Eur J Endocrinol 2006; 154:119-124.

-5 Paterson WF, McNeill E, Reid S, Hollman AS, Donaldson MD: Efficacy of Zoladex LA (goserelin) in the treatment of girls with central precocious or early puberty. Arch Dis Child 1998;79:323-327.

-6 Trueman JA, Tillmann V, Cusick CF, Foster P, Patel L, Hall CM, Price DA, Clayton PE: Suppression of puberty with long-acting goserelin (Zoladex LA): effect on gonadotrophin response to GnRH in the first treatment cycle. Clin Endocrinol 2002;57:223-230.

-7 Arrigo T, De Luca F, Antoniazzi F, Galluzzi F, Segni M, Rosano M, Messina MF, Lombardo F: Reduction of baseline body mass index under gonadotropin-suppressive therapy in girls with idiopathic precocious puberty. Eur J Endocrinol 2004;150:533537.

-8 Feuillan PP, Jones JV ,Barnes K, OerterKlein K, Cutler GB Jr: Reproductive axis after discontinuation of gonadotropin-releasing hormone analog treatment of girls with precocious puberty: long-term follow-up comparing girls with hypothalamic hamartoma to those with idiopathic precocious puberty. J Clin Endocrinol Metab 1999;84:4449.
9 Heger S, Partsch CJ, Sippell WG: Long-term outcome after depot gonadotropin-releasing hormone agonist treatment of central precocious puberty: final height, body proportions, body composition, bone mineral density, and reproductive function. J Clin Endocrinol Metab 1999;84:4583-4590.

10 Palmert MR, Mansfield MJ, Crowley WF Jr, Crigler JF Jr, Crawford JD, Boepple PA: Is obesity an outcome of gonadotropin-releasing hormone agonist administration? Analysis of growth and body composition in 110 patients with central precocious puberty. J Clin Endocrinol Metab 1999;84:44804488.

-11 Lazar L, Kauli R, Pertzelan A, Phillip M: Gonadotropin - suppressive therapy in girls with early and fast puberty affects the pace of puberty but not the total pubertal growth or final height. J Clin Endocrinol Metab 2002;87:2090-2094.

$\checkmark 12$ Neely EK, Wilson DM, Lee PA, Stene M, Hintz RL: Spontaneous serum gonadotropin concentrations in the evaluation of precocious puberty. J Pediatr 1995;127:47-52.

13 Freeman JV, Cole TJ, Chinn S, Jones EM, Preece MA: Cross sectional stature and weight reference curves for the UK, 1990. Arch Dis Child 1995;73:17-24.

14 Cole TJ, Freeman JV, Preece MA: Body mass index reference curves for the UK, 1990. Arch Dis Child 1995;73:25-29.

15 Bouvattier C, Lahlou N, Roger M, Bougnères $\mathrm{P}$ : Hyperleptinaemia is associated with impaired gonadotrophin response to $\mathrm{GnRH}$ during late puberty in obese girls, not boys. Eur J Endocrinol 1998;138:653-658.

16 Weise M, Flor A, Barnes KM, Cutler GB Jr, Baron J: Determinants of growth during gonadotropin-releasing hormone analog therapy for precocious puberty. J Clin Endocrinol Metab 2004;89:103-107.
17 Walvoord EC, Pescovitz OH: Combined use of growth hormone and gonadotropin-releasing hormone analogues in precocious puberty: theoretic and practical considerations. Pediatrics 1999;104:1010-1014.

18 Oostdijk W, Rikken B, Schreuder S, Otten B, Odink R, Rouwe C, Jansen M, Gerver WJ, Waelkens J, Drop S: Final height in central precocious puberty after long term treatment with a slow release GnRH agonist. Arch Dis Child 1996;75:292-297.

19 Paterson WF, McNeill E, Young D, Donaldson MDC: Auxological outcome and time to menarche following long-acting goserelin therapy in girls with central precocious or early puberty. Clin Endocrinol 2004;61:626634.

20 van der Sluis IM, Boot AM, Krenning EP, Drop SLS, de Muinck Keizer-Schrama SMPF: Longitudinal follow-up of bone density and body composition in children with precocious or early puberty before, during and after cessation of GnRH agonist therapy. J Clin Endocrinol Metab 2002;87:506-512.

21 Kaplowitz PB, Slora EJ, Wasserman RC, Pedlow SE, Herman-Giddens ME: Earlier onset of puberty in girls: relation to increased body mass index and race. Pediatrics 2001;108: 347-353.

22 Pietrobelli A, Faith MS, Allison DB, Gallagher D, Chiumello G, Heymsfield SB: Body mass index as a measure of adiposity among children and adolescents: a validation study. J Pediatr 1998;132:204-210.

23 Boot AM, de Muinck Keizer-Schrama SMPF, Pols HAP, Krenning EP, Drop SLS: Bone mineral density and body composition before and during treatment with gonadotropin-releasing hormone agonist in children with central precocious and early puberty. J Clin Endocrinol Metab 1998;83:370-373.

24 Brito VN, Latronico AC, Arnhold IJP, Mendonca BB: A single luteinising hormone determination $2 \mathrm{~h}$ after depot leuprolide is useful for therapy monitoring of gonadotropin-dependent precocious puberty in girls. J Clin Endocrinol Metab 2004;89:4338-4342. 